indifference or acceptance does not mean that they are not interested but simply that they have never been asked and that they have never been told what the nursing process is.

Nothing should be introduced without built-in evaluation-Only half a century ago, medicine was a literate but not a numerate profession and many of the confident statements in our books and papers of the day were no more soundly based than the present claim that the nursing process will improve patient care. Before any further steps are taken to introduce the nursing process, its advocates must set down very simply the ways in which they believe that patient care and wcll being will be improved. We must then measure these indices before and after the process or on wards that do or do not adopt it. Until there has been adequate evaluation, the successor body to the General Nursing Council (the United Kingdom Central Council) should refrain from seeking to impose the nursing process on reluctant institutions by threatening to withhold their training recognition.

Anything that takes nurses away from patients is to be deploredThe spectacle of a row of nurses beavering away at complex and irrelevant checklists fills me with gloom; the documents should be the servant of nursing care and not its master.

Patient care cannot be done by committee, and responsibilities rather than rights should guide us-At present, the legal buck stops with the consultant or principal in general practice to whose care the patient has been entrusted. Employing authorities are alarmed at the suggestion that patients on a ward may be admitted by nurses, without being under the care of a doctor, or that there may be nursing documents, subserving a nursing diagnosis and a nursing plan, which are independent from or even in opposition to the medical diagnosis and the medical plan. I do not believe that two people can be equally in charge of one patient.

\section{Quo Vadis?}

I hope that nursing and medicine can devise a synthesis which will address itself to the two key questions that Florence Nightingale identified-what is a nurse ? and how should nurses and doctors work together in the provision of patient care? "No taxation without representation" was a rallying cry for our forefathers and I hope that my readers now see the need to become familiar with the nursing process so that they can join in an informed debate about it under the banner of "No introduction without discussion and evaluation." I am delighted to find that this is not just a personal or a medical view but is being actively supported by the nurses themselves" : "We should get our own act together in terms of the nursing process and start looking at what this type of approach really means to us and how it can help our professional practices and our patients. We should no longer pay lip service to the idea or hide behind a mountain of history sheets, nursing care plans, and other forms of communication. Unless we can come to terms with the commonsense principles of the nursing process approach and show in practical terms that we understand it ourselves, we are never going to have any success in describing to others how we, as nurses, contribute to the overall care of patients."

\section{References}

1 Woodham-Smith C. Florence Nightingale 1820-1910. London: The Reprint Society, 1952:153.

2 Woodham-Smith C. Florence Nightingale 1820-1910. London: The Reprint Society, 1952:271.

${ }^{3}$ Anonymous. Nursing process criticised. $\mathrm{Br} M e d \mathcal{f} 1983 ; 287: 439,441$.

4 Yura H, Walsh M. The nursing process. New York: Appleton-CenturyCrofts, 1978.

${ }^{5}$ Baroness Macfarlane of Llandaff, Castledine G. A guide to the practice of nursing using the nursing process. London: C V Mosby, 1982.

6 Bowman MP. Nursing by lamplight. The Health Services 1983;46:10-11.

7 Royal College of Nursing of the United Kingdom. Standards of nursing care. London: Royal College of Nursing, 1980.

${ }^{8}$ Royal College of Nursing of the United Kingdom. Towards standards. London: Royal College of Nursing, 1981.

${ }^{9}$ Ride T. Do we understand the process? Nursing Mirror 1983;Aug 17: 12-13.

${ }^{10}$ Roper N, Logan WW, Tierney AJ. Using a model for nursing. Edinburgh: Churchill-Livingstone, 1983.

11 Clay T. Nurses are not doctors. The Health Services 1983;47:7.

(Accepted 19 September 1983)

\title{
Doctors can work with the nursing process: a reply to Professor Mitchell
}

\author{
RAY ROWDEN
}

The history and development of nursing require examination. The popular image of nurses as compliant and devoted flows from the misconceptions held about the history of the profession. People are inclined to rely on the work of Florence Nightingale and presume that her model for nursing is sacrosanct, but traditional images are now being challenged. ${ }^{1}$ Contrary to popular belief, Florence Nightingale did not have things all her own way. She felt that the probationer nurse could survive on six months of training and needed to be solidly built. Ethel Bedford Fenwick, a doctor's wife, had different views and saw the need for an academic training for the nurse practitioner;

\section{Royal Marsden Hospital, London SW3}

RAY ROWDEN, SRN, RMN, director of nursing services

Correspondence to: Royal Marsden Hospital, Downs Road, Sutton, Surrey SM2 5PT. much of her work was to influence the shape of the first piece of legislation for nurses in 1919.2 Both women had groups of supporters and each group argued its case, often vitriolically. An understanding of the history of the profession is important in relation to changes in patterns of nursing care.

At the Royal Marsden Hospital we use the nursing process in all wards and have done so for a number of years. I would like to share some of the thinking behind our approach to care and some of our experiences.

\section{The nature of nursing}

The nursing and medical professions are totally interdependent, it is therefore essential that we learn to share major issues, establish dialogue, and learn to accommodate each other maturely. The demands placed on the nurse today are radically different from those of 20 years ago. The nurse needs to have 
well developed skills of communication, great sensitivity, and a good degree of manual dexterity. In many aspects of clinical practice she also needs sound knowledge and flexibility, for the ever increasing specialisation in medicine is reflected in developments in nursing, and we are constantly asking nurses to extend their role.

The development of an overall view of the patient has always been the basis of sound medical practice. In reality, however, the average amount of time that doctors and other health care workers can give to each patient is limited. Nurses do have time to give to people faced with illness, disability, or the prospect of death and are the only health workers in close and continuous contact with patients. This is what makes nursing unique.

Nursing cannot be defined as a science in the purest form; we draw on a host of sciences to form a body of knowledge that is relevant to caring for people. I would also venture to suggest that giving care entails a good measure of intuition, and that nursing is also an art. In traditional patterns of nursing care is broken down into a series of ranked tasks. Thus the most junior nurse can clean the sluice, the nurse on the next level can carry out the dressings, until we reach the dizzy heights of the staff nurse, who is allowed to fill in the stationery requisition. I worked in this framework for many years and know the effect that it has on care. Allocation of tasks leads to fragmentation of care and moves the nurse away from the patient as she becomes more experienced. Many factors have caused nurses to look anew at patterns of care. Nurses work fewer hours, and more are married and work part time. Duration of stay in hospital has reduced, and technological demands have mushroomed.

\section{Message behind the nursing process}

Against this backdrop the nursing process proves its worth in a number of ways. It is said that the nursing process is tied up in highbrow transatlantic jargon and theories. I accept this criticism to some degree, but it applies equally to the study of management, sociology, and psychology, and I do not reject these sciences and hypotheses simply because I have to wade through a plethora of heavy reading to get the message. The message behind the nursing process is simple. It is essentially about each nurse taking individual responsibility for the care given to each patient and thinking intelligently and systematically about that care. Admission to hospital and illness are traumatic events, yet traditional patterns of nursing do little to help the patient adjust. Imagine entering hospital and being admitted by one nurse, having another feeding you, another washing you, another giving drugs, another recording physiological measurements, and so on. It does not make sense to fragment care in this way.

The nursing process also demands that care be individually planned for the patient, respecting his wishes where feasible. In the past we ran hospitals fairly rigidly: people were expected to go to bed at a set time, rise at a set time, and be visited by loved ones at a set time. I can even remember wards where patients were expected to use commodes and urinals at set times. If a person's normal habit is to go to bed at midnight and rise at 9 am, why should hospital interfere with that norm? If an individual likes a gin and tonic with the six o'clock news, why should hospital stop that habit, where there are no contraindications? It is when we face trauma that we most need to cling to aspects of normality. How often do we deprive people of normality at the time they most need it?

The starting point of the nursing process entails taking a history that will elicit information not primarily related to medical diagnosis. Using this history, coupled with information from medical colleagues, the nurse can begin to think about the care the patient needs and the form that care should take. This should mean that not all patients admitted for routine surgery will necessarily be starved from midnight, and that there will not be automated nursing with emotional detachment.

The other common myth about the nursing process is that it creates mountains of paper; in our experience the reverse is the case. We have reduced paperwork by experimenting with various care plans and evaluating the results carefully. If we invest time in taking a nursing history and in planning, we need write only what is essential and meaningful. If you read a standard nursing Kardex you would find a crop of meaningless entries, religiously charted day after day. Some examples of this are: "good day," "big bath," "difficult today," and "a bit low," none of which tell us anything of value about the patient. Kardex encourages the view that something must be written every day about every patient; this is a waste of nursing time. In a problem orientated plan the nurse needs to write only when a problem and the care related to it change.

From a medicolegal view the problem orientated plan is a blessing. I worked for the Royal College of Nursing for three years, representing nurses in a variety of tribunals, inquiries, and disciplinary hearings. It was always easier to represent a member with problem orientated records. In a complicated case it was difficult to wade through months of Kardex entries in date order to find information essential to the construction of a defence.

The nursing process recognises that more nurses work fewer hours. We must have a reliable method of record keeping that will allow a nurse to obtain, easily and quickly, a complete picture of a patient's nursing needs. The suggestion that the advent of the nursing process has diminished the contribution of doctors to nurse education does not accord with our experience. Medical diagnosis will always be relevant to nursing.

\section{Importance of teamwork}

Some doctors express fear when nurses state that there may be conflict in the goals of health workers; this notion has been with us for years and needs to be faced. Where patients have a range of options for treatment, genuine teamwork is essential in reaching management decisions. Nurses, as well as doctors and other professionals, must satisfy themselves that all options have been considered in a balanced and ethical manner, for Professor Mitchell is mistaken in his view that only doctors carry legal responsibilities. The nurse is answerable in law for her own actions as a practitioner, and no other person can assume that responsibility. If a nurse is party to a treatment that is not soundly based and that goes wrong, the disciplinary committee of the statutory nursing body will want to know what she did to satisfy herself that the treatment was ethical and what part she played. It will do her no good to say, "I did it because the doctor told me to"; and I have yet to find the court that will call a doctor before them to explain nursing actions related to nursing performance. The nurse owes a duty of care to her patients. Part of the nurse's legal duty to her patients entails challenging decisions that appear to contradict the interests of patients. ${ }^{3}$ This has always been the case-the nursing process simply restates this. The nurse can also be questioned or challenged by other nurses and other professional colleagues. Where there are shades of grey-for example, in oncology and psychiatry-where no single profession can claim a monopoly on wisdom, openness and mutual trust between the professions will ensure that the patient gets the best that is available.

It is obvious that as research and knowledge increases we will have to tackle ethical dilemmas more often. If we spend less time acting like prima donnas and more on developing an atmosphere in which we can share problems, genuine teamwork may well have the chance to work. May I extend Professor Mitchell's orchestral analogy to medical leadership? In Tchaikowsky's violin concerto the solo violin for a time assumes a far greater importance to the whole work than the conductor. Equally, few orchestras use one conductor only: Mutti is known for certain skills, Sir Charles Groves for others. It is the same in health care. At some times it will be the nurse who assumes the most important role in relation to the patient, at other times it will be the doctor, the speech therapist, etc, and the roles of all professionals need to change and counterbalance in relation to the 
changing needs of the patient. This is not care by committee, it is sensible use of expensive personnel, recognising that no single profession has all the answers all the time.

It is said that the nursing process is not researched. Professor Mitchell suggests that medicine provides a model of perfection in research. If this is the case, why has nobody given adequate time to research into the use of electroconvulsive therapy ? Why did nobody insist on adequate research in the 1950s and ' 60 s, when we undertook some fairly crude operations on the brain, all in the name of psychosurgery? There are other examples. Much of the thinking behind the nursing process has been tested by highly respected nurse researchers. Many studies published by the Royal College of Nursing show that individual care can affect outcome for the patient. Departments of nursing research are beginning to blossom in Britain. I hope that a centre will undertake a major piece of work related to models for nursing care; evidence is already available to support the nursing process.

Professor Mitchell also misunderstands the extended role of the nurse. In my own hospital nurses undertake nearly all intravenous work, but not one is in possession of a certificate signed by a doctor-the law does not demand this. What our own professions demand is that where a nurse extends her function there must be mutual agreement between the professions as to the shape and scope of the extended role. ${ }^{4}$ When agreement is reached, the law demands that extension is ratified not by a consultant but by the employing authorities.

Professor Mitchell raises some interesting issues. I know that he echoes the fears and anxieties of some colleagues and it is essential that we maintain a dialogue. I can assure readers that relationships between nurses and doctors at the Royal Marsden are sound, the best I have experienced; the nursing process does not have to threaten these relationships. Perhaps there would be greater understanding if students of health care trained together for some first and final year studies and if we developed more joint projects at postgraduate levels.

Florence Nightingale's questions about relations between our professions remain relevant, but there are no clear cut answers. In my view genuine teamwork is the best model for the provision of health care, and the nursing process can do much to help the development of the nurse's contribution to the team. I look forward to many more years of help and cooperation from medical colleagues in the education of nurses; equally, I hope that the experienced nurse will continue to help the education of the junior houseman.

\section{References}

${ }^{1}$ Davies C, ed. Rewriting nursing history. London: Croom-Helm, 1981.

2 Bowman G. The lamp and the book. London: Royal College of Nursing, 1967:48-56.

${ }^{3}$ Royal College of Nursing. Memorandum from legal department. London: Royal College of Nursing, 17 November 1982.

4 Royal College of Nursing/British Medical Association. The duties and position of the nurse. Revised edition. London: Royal College of Nursing, 1978.

(Accepted 16 November 1983)

\title{
Lesson of the Week
}

\section{Acute schistosoniasis (Tatajana fever)}

\author{
P C STUIVER
}

Three clinical syndromes are recognised as manifestations of infection by the three main trematode species in human schistosomiasis (Schistosoma mansoni, $S$ haematobium, and $S$ japonicum $)^{1}$ : (1) swimmers' itch or dermatitis due to cercarial penetration of the skin; (2) acute schistosomiasis or Katayama fever, which coincides with larval maturation and migration and early oviposition; (3) chronic schistosomiasis, in which the lesions are the result of the inflammation and subsequent fibrosis caused by the schistosoma eggs.

Infection is acquired by exposure to water containing cercarias released by certain infected snails, the intermediate host. The cercarias swim until they come into contact with a suitable definitive host. Within 24 hours of the skin being penetrated by the cercarias some patients experience intense itching, sometimes followed by a papular rash (cercarial dermatitis). This may last for two or three days and is therefore almost never seen in Western Europe. The syndrome of acute schistosomiasis usually develops three to six weeks after the initial infection and may last for three to four months. Until recently ${ }^{2}{ }^{3}$ it also was an imported disease that was rarely seen. The numbers of people travelling to the tropics by air have greatly increased

Department of Tropical Medicine, Havenziekenhuis, 3011 TD

Rotterdam, Netherlands

P C STUIVER, MD, professor of exotic diseases 